\title{
A review and meta-analysis of red and processed meat consumption and breast cancer
}

\author{
Dominik D. Alexander ${ }^{1}$, Libby M. Morimoto ${ }^{2}$, Pamela J. Mink ${ }^{3}$ and Colleen A. Cushing ${ }^{1}$ \\ ${ }^{1}$ Exponent Health Sciences Practice, Wood Dale, IL, USA \\ ${ }^{2}$ Exponent Health Sciences Practice, Menlo Park, CA, USA \\ ${ }^{3}$ Emory University, Atlanta, GA, USA
}

\begin{abstract}
The relationship between meat consumption and breast cancer has been the focus of several epidemiological investigations, yet there has been no clear scientific consensus as to whether red or processed meat intake increases the risk of breast cancer. We conducted a comprehensive meta-analysis incorporating data from several recently published prospective studies of red or processed meat intake and breast cancer. In the meta-analysis utilising data from the Pooling Project publication (includes data from eight cohorts) combined with data from nine studies published between 2004 and 2009 and one study published in 1996, the fixed-effect summary relative risk estimate (SRRE) for red meat intake (high $v$. low) and breast cancer was $1.02(95 \%$ CI 0.98, 1.07; $P$ value for heterogeneity $=0.001)$ and the random-effects SRRE was $1.07(95 \%$ CI $0.98,1 \cdot 17)$. The SRRE for each $100 \mathrm{~g}$ increment of red meat was 1.04 (95\% CI 1.00, 1.07), based on a fixed-effects model, and 1.12 (95\% CI 1.03, 1.23) based on a random-effects model. No association was observed for each $100 \mathrm{~g}$ increment of red meat among premenopausal women (SRRE 1.01; $95 \%$ CI 0.92, 1.11) but a statistically significant SRRE of 1.22 (95\% CI 1.04, 1.44) was observed among postmenopausal women using a random-effects model. However, the association for postmenopausal women was attenuated and non-significant when using a fixedeffects model (SRRE 1.03; $95 \%$ CI 0.98, 1.08). The fixed- and random-effect SRRE for high (v. low) processed meat intake and breast cancer were 1.00 (95\% CI $0.98,1.01 ; P$ value for heterogeneity $=0.005)$ and $1.08(95 \%$ CI 1.01, 1.16), respectively. The fixed- and random-effect SRRE for each $30 \mathrm{~g}$ increment of processed meat were 1.03 (95\% CI 1.00, 1.06) and 1.06 (95\% CI $0.99,1.14)$, respectively. Overall, weak positive summary associations were observed across all meta-analysis models, with the majority being non-statistically significant. Heterogeneity was evident in most analyses, summary associations were sensitive to the choice of analytical model (fixed $v$. random effects), and publication bias appeared to have produced slightly elevated summary associations. On the basis of this quantitative assessment, red meat and processed meat intake does not appear to be independently associated with increasing the risk of breast cancer, although further investigations of potential effect modifiers, such as analyses by hormone receptor status, may provide valuable insight to potential patterns of associations.
\end{abstract}

Breast cancer: Meta-analyses: Diet: Nutrition: Epidemiology

\section{Introduction}

Although the association between diet and breast cancer has been investigated extensively, the overall evidence surrounding the potential relationship between dietary factors and breast cancer carcinogenesis has resulted in the identification of very few risk factors. As with most dietary factors, the association between meat consumption and breast cancer has been equivocal ${ }^{(1)}$. Some early US and international ecological studies reported positive correlations between rates of breast cancer and per capita intake of meat ${ }^{(2-6)}$, and several factors, such as heterocyclic amines, $N$-nitroso compounds, polycyclic aromatic hydrocarbons and haem $\mathrm{Fe}$, have been hypothesised as contributing to breast cancer. However, analytical epidemiological studies that assessed red meat and processed meat as dietary intake variables have not corroborated these findings, as associations across cohort and case-control studies have been variable. In a 1993 meta-analysis of seven

Abbreviations: ER, oestrogen receptor; PR, progesterone receptor; RR, relative risk; SSRE, summary relative risk estimate.

* Corresponding author: Dr Dominik D. Alexander, email dalexander@exponent.com 
cohort and case-control studies, Boyd et al. ${ }^{(7)}$ reported a statistically significant positive association (summary estimate $=1.54 ; 95 \%$ CI $1.31,1.82$ ) between red meat intake and breast cancer. In contrast, slight inverse associations for consumption of red meat (summary relative risk (RR) for each $100 \mathrm{~g} / \mathrm{d}$ increment $=0.98,95 \%$ CI 0.93 , 1.04 ) or processed meat (summary RR for each $10 \mathrm{~g} / \mathrm{d}$ increment $=0.98,95 \%$ CI $0.96,1.00)$ were reported in the comprehensive analysis of the Pooling Project of Prospective Studies of Diet and Cancer published in $2002^{(8)}$. In a recent meta-analysis among premenopausal women, a nonsignificant summary association of 1.11 (95\% CI 0.94, 1.31) was reported across three cohort studies, although data from seven cohorts that were analysed in the Pooling Project publication were not included in the analysis ${ }^{(9)}$.

Since these analyses, several large prospective studies have been published that may provide enhanced clarification to any potential associations between red meat consumption and breast cancer. Specifically, evaluations of the NIHAARP Diet and Health Study ${ }^{(10,11)}$, Swedish Mammography Cohort ${ }^{(12)}$, European Prospective Investigation into Cancer and Nutrition (EPIC) ${ }^{(13)}$, Prostate, Lung, Colorectal, and Ovarian (PLCO) Cancer Screening Trial ${ }^{(14)}$, Diet Cancer and Health Cohort ${ }^{(15)}$, Shanghai Breast Self Exam Trial $^{(16)}$, UK Women's Cohort Study ${ }^{(17)}$, Monitoring Project on CVD Risk Factors ${ }^{(18)}$ and the Nurses' Health Study (I and II) ${ }^{(19-22)}$ have been published that provided data on red meat consumption and breast cancer. Therefore, to further update the state of the science, we conducted a review and meta-analysis of prospective cohort studies of red meat or processed meat intake and female breast cancer. We performed high $v$. low intake meta-analyses, dose-response examinations, heterogeneity assessments, sensitivity and influence evaluations, and an appraisal of publication bias.

\section{Materials and methods}

\section{Literature search and study inclusion}

We conducted a MEDLINE literature search using the PubMed interface to identify articles eligible for review. All articles indexed by PubMed that were published up to July 2009 were included. The literature search string included: breast cancer OR breast cancers OR breast neoplasm OR breast neoplasms AND (diet* OR diet OR nutrition OR food OR meat OR beef OR pork OR lamb). In addition to the literature search, the bibliographies of review articles pertaining to diet and breast cancer were examined in an effort to identify all available literature that may not have been identified by our database searches. Peer-reviewed publications of prospective cohort studies or nested casecontrol studies that evaluated red meat or processed meat consumption and female breast cancer were included. Case-control studies, ecological assessments, correlation studies and other publications of aggregate-level analyses were excluded, as were experimental animal studies and mechanistic studies.

Red meat is commonly defined as beef, pork, lamb, or a combination thereof, and processed meat is generally defined as meat made largely from pork, beef or poultry that undergoes methods of preservation, such as curing, smoking or drying ${ }^{(23,24)}$. Most studies reported associations for categories labelled as 'red meat' or 'processed meat'; however, several studies reported results for individual red (for example, beef, pork) and/or processed (for example, hot dogs, bacon) items. The definitions of red meat and processed meat as a food category varied across studies. While many studies explicitly defined these classifications, other studies reported no description. Studies that reported data for a broad classification of meat, such as 'total meat' categories, which included poultry or fish, were excluded. Studies that reported information pertaining to constituents of red meat, such as fat or protein from animal sources, heterocyclic amine exposure, or cooking practices, were obtained but analysis of these factors was beyond the scope of the present assessment. RR and measures of variability (i.e. $95 \% \mathrm{CI}$ ) for consumption categories of red or processed meat intake using the lowest category of intake as the reference, or available data for such calculations, were required to be reported in the included articles.

\section{Data extraction}

Qualitative information and quantitative data were extracted from each study that met the criteria for inclusion. Specifically, information was extracted pertaining to: the year of the study, the study population (i.e. name and nature of the cohort), geographical location of the study, years of follow-up, methods of dietary exposure ascertainment, red meat and processed meat dietary variables and how these variables were defined, the analytical comparison (i.e. the exposure contrast), the number of exposed cases, the RR estimates and $95 \% \mathrm{CI}$, and the factors that were adjusted or controlled for in the analyses.

A thorough review of each article was conducted to identify cohorts that may have been analysed in multiple publications. If results were reported in multiple publications, the inclusion of data was based on (1) the size of the study population, (2) duration of follow-up with an emphasis on the most recent publication with the longest follow-up, (3) classification and analytical categorisation of red or processed meat, and (4) level of control for potential confounding factors. Data from the Missmer et al. ${ }^{(8)}$ publication were used, which was an analysis of the Pooling Project of Prospective Studies of Diet and Cancer ${ }^{(25)}$, in the primary meta-analysis models. Specifically, Missmer et al. ${ }^{(8)}$ analysed primary data from eight individual study cohorts from North America and Western Europe, contributing 7379 cases of breast cancer. Data from independent publications of the Nurses' Health Study ${ }^{(22,26)}$, the Seventh Day Adventist Cohort ${ }^{(27)}$ and the Netherlands Cohort Study ${ }^{(28)}$ were not included in the model with Missmer et al. ${ }^{\left({ }^{(3)}\right.}$ because these study populations were analysed in the Pooling Project. Data from these studies were included in a separate meta-analysis model that did not include Missmer et al. ${ }^{\left({ }^{(8)}\right.}$. Missmer et al. ${ }^{(8)}$ evaluated data for 1320 breast cancer cases from the Swedish Mammography Cohort during 10 years of followup (1987-1997). In a 2009 update of the Swedish Mammography Cohort, Larsson et al. ${ }^{(12)}$ analysed 2952 breast cancer cases during 20 years of follow-up (19872007). Thus, data from Larsson et al. ${ }^{(12)}$ were included 
in the primary meta-analyses with Missmer et al. ${ }^{(8)}$ and data from Larsson et al. ${ }^{(12)}$ were removed in the sensitivity analyses. Two publications of the Nurses' Health Study I and II cohorts were identified that analysed diet during pre-school $^{(21)}$ and adolescence ${ }^{(20)}$. Data from these studies were not included in the meta-analysis models because of likely population overlap with other studies. In addition, these studies differed from the other studies included in this assessment in regards to the methodology of past dietary exposure ascertainment and the analysis of diet during early life-time periods. The characteristics of all cohort and nested case-control studies reviewed in the present paper are summarised in Table 1.

\section{Statistical analyses}

Meta-analyses comparing the highest intake category of red meat or processed meat with the lowest (or referent) intake category were conducted. Meta-analysis models were constructed for overall red meat or processed meat groups as well as for individual meat items where applicable (for example, hot dogs, bacon, organ products). In two studies ${ }^{(12,19)}$ that reported data for total red meat (including processed meat items) and red meat only, data were selected specifically for red meat (without processed meat items). Separate metaanalyses were generated among the studies that reported data by menopausal status. Additionally, meta-analyses of doseresponse categorical data were conducted using the method proposed by Greenland \& Longnecker ${ }^{(29)}$, in which the linear dose-response slope is calculated for each study while accounting for the correlation across intake categories within a study ${ }^{(30)}$. If the number of cases and person-time data were not available for each intake strata, variance-weighted least squares regression was utilised to estimate the slope coefficient. Different intake units were reported across studies; therefore, we used $80 \mathrm{~g}$ as the approximate serving size for red meat and $30 \mathrm{~g}$ for processed meat.

Fixed-effects and random-effects models were used to calculate summary RR estimates (SRRE), 95\% CI, and corresponding $P$ values for heterogeneity. In the 'one study removed' sensitivity analyses, the relative influence of each study on the model-specific SRRE was examined by generating an SRRE based on all studies in a particular model, followed by the removal of one study at a time in order to compare the overall SRRE with SRRE from models that had one study removed. The presence of publication bias was assessed visually by examining a funnel plot measuring the standard error as a function of effect size, as well as performing Duval and Tweedie's trim and fill method ${ }^{(31)}$. All statistical analyses were performed using STATA (version 10.0; StataCorp LP, College Station, TX, USA), Comprehensive Meta-Analysis (version 2.2.046; Biostat, Englewood, NJ, USA) and Episheet ${ }^{(32)}$. The utilisation of independent analytical programs allowed for the validation of calculations.

\section{Results \\ Red meat}

No significant association between the highest category of red meat intake compared with the lowest category of intake and breast cancer was observed in the meta-analysis model that included data from the Pooling Project publication (eight cohorts) combined with data from ten additional studies (SRRE for fixed-effects model $=1 \cdot 02 ; 95 \%$ CI $0.98,1.07 ; P$ value for heterogeneity $=0.001$ ) (Fig. 1; Table 2). The SRRE for the random-effects model was slightly stronger in magnitude (SRRE 1.07; $95 \%$ CI 0.98, $1 \cdot 17$ ), primarily because this model provided only $16 \%$ of the relative weight to the pooled analysis of eight cohorts by Missmer et al. ${ }^{(8)}$. Byrne et al. ${ }^{(33)}$ reported data only for beef consumption; therefore, this study was removed as part of the sensitivity analysis. This study had less than $1 \%$ of relative weight, so the overall summary estimate remained virtually unchanged with its removal. In the one study removed influence analysis, the removal of any single study did not appreciably alter the overall SRRE by more than $4 \%$. When Larsson et al. ${ }^{(12)}$ was removed (partial overlap with Missmer et al. ${ }^{(8)}$ ), the fixed- and random-effects summary associations became 1.04 (95\% CI 0.99, 1.08; $P$ value for heterogeneity $=0.002)$ and $1.10(95 \% \mathrm{CI} 1.00$, $1 \cdot 21)$, respectively. Replacing the data from Missmer et al. ${ }^{\left({ }^{8}\right)}$ with data from studies that analysed populations included in the Pooling Project (i.e. Holmes et al. ${ }^{(22)}$, Mills et al. ${ }^{(27)}$ and Voorrips et al. ${ }^{(28)}$ ) did not markedly modify the overall summary associations (SRRE for fixed-effects model $=1.03 ; \quad 95 \%$ CI $0.99, \quad 1.08 ; \quad P$ value for heterogeneity $=0.005 ; \quad \mathrm{SRRE}$ for random-effects model $=1.06 ; 95 \%$ CI $0.98,1.15)$ nor did this model explain the observed heterogeneity. The summary associations in a sensitivity analysis that included only studies $^{(11-19,22)}$ published after the Pooling Project publication were similar in magnitude to the overall association (fixed-effects SRRE 1.05; $95 \%$ CI 1.00, 1.10; $P$ value for heterogeneity $=0.023$; random-effects SRRE 1.08; $95 \%$ CI 1.00, 1.17) (Table 2).

The SRRE for the studies that reported data for red meat and breast cancer among premenopausal women was 1.02 (95\% CI $0.92,1.13$; $P$ value for heterogeneity $=0.268$; fixed-effects model) (Table 2). The fixed-effects SRRE among studies that reported red meat intake data for postmenopausal women was 1.02 (95\% CI 0.98, 1.08; $P$ value for heterogeneity $=0.005)$, while the summary association in the random-effects model was slightly stronger (SRRE 1.11; $95 \%$ CI $0.99,1.25$ ), largely due to the reduction of relative weight given to the pooled analysis by Missmer et al. ${ }^{(8)}$.

In the categorical dose-response meta-analysis, the SRRE for each $100 \mathrm{~g}$ increment of red meat intake was 1.04 $(95 \%$ CI 1.00, 1.07; $P$ value for heterogeneity $<0.0001)$ in the fixed-effects model and $1.12(95 \%$ CI 1.03, 1.23) in the random-effects model. Among premenopausal women, the summary association for each $100 \mathrm{~g}$ increment of red meat was 1.01 (95\% CI 0.92, 1.11; fixed effects) with a nonsignificant $P$ value for heterogeneity $(P=0 \cdot 316)$. Among postmenopausal women, the fixed-effects and randomeffects SRRE for each $100 \mathrm{~g}$ increment of red meat intake were $1.03 \quad(95 \%$ CI $0.98,1.08 ; P$ value for heterogeneity $<0.0001$ ) and 1.22 (95\% CI 1.04, 1.44), respectively. Modest differences in summary associations by model were observed among postmenopausal women, largely due to the fact that the random-effects model 


\section{NS Nutrition Research Reviews}

Table 1. Summary of cohort studies of red meat and processed meat and female breast cancer

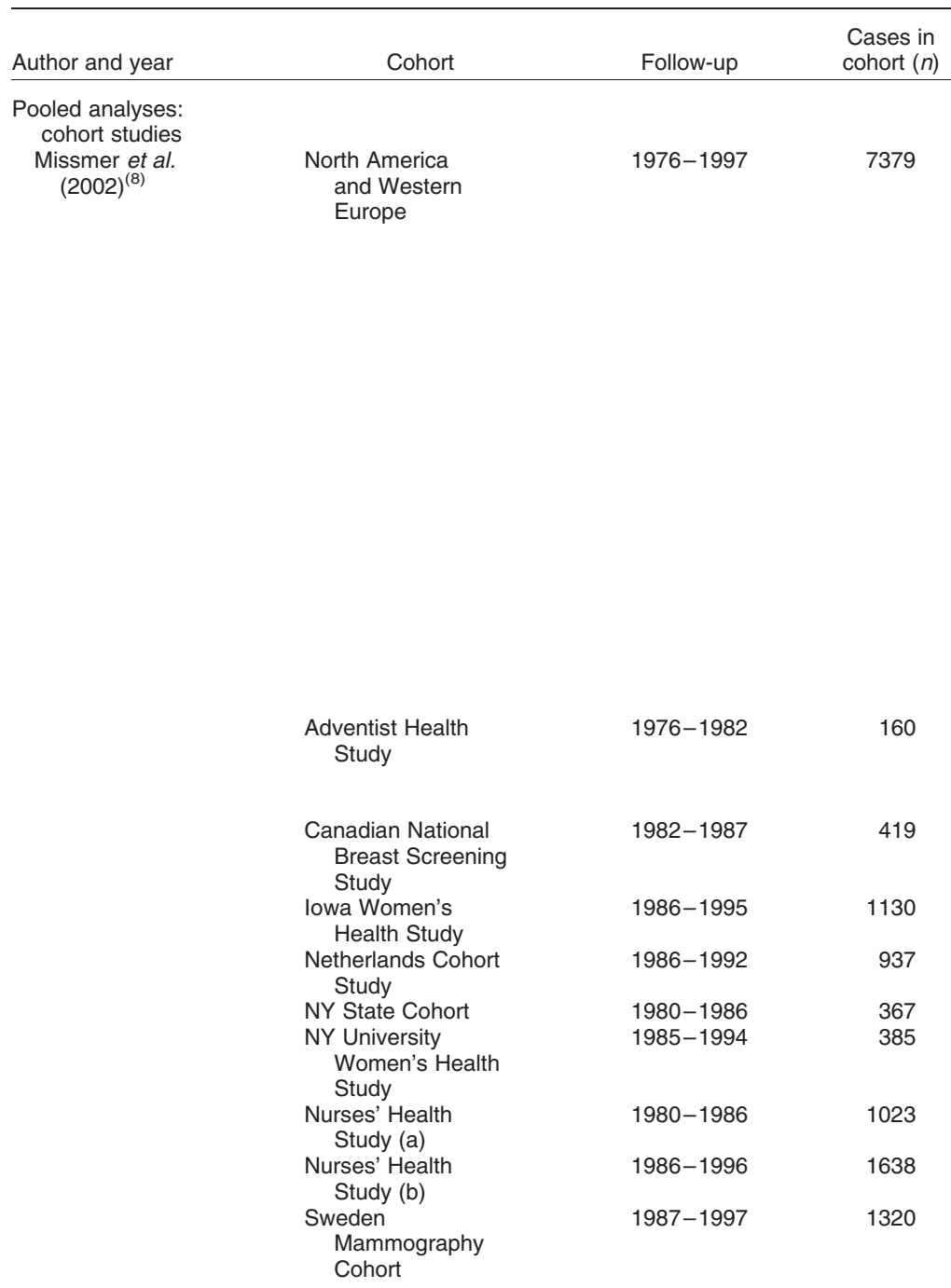

Per $100 \mathrm{~g}$ per $\mathrm{d}$

increment in

consumption
All women

Premenopausal

women

Postmenopausal

women
Relative risk

estimate* $^{*}$

$95 \% \mathrm{Cl}$

Statistical adjustment

beef, roast beef, beef

Quartiles

blood pudding, ham, ho

$0.94 \dagger$

$0.87,1.02$

Age at menarche

teraction between

parity and age

irst birh, oral

chen liver, pork live

sausage, processed

uncheon meats, white

meat, eggs, and total

meat products)

history of benign

family history of

family history of

smoking status,

smoking status,

education, BMI,

intake, acohol

intake, total energy
intake, menopausa

intake, menopausa

status, interaction

pausal status,

pausal status,

hormone use 

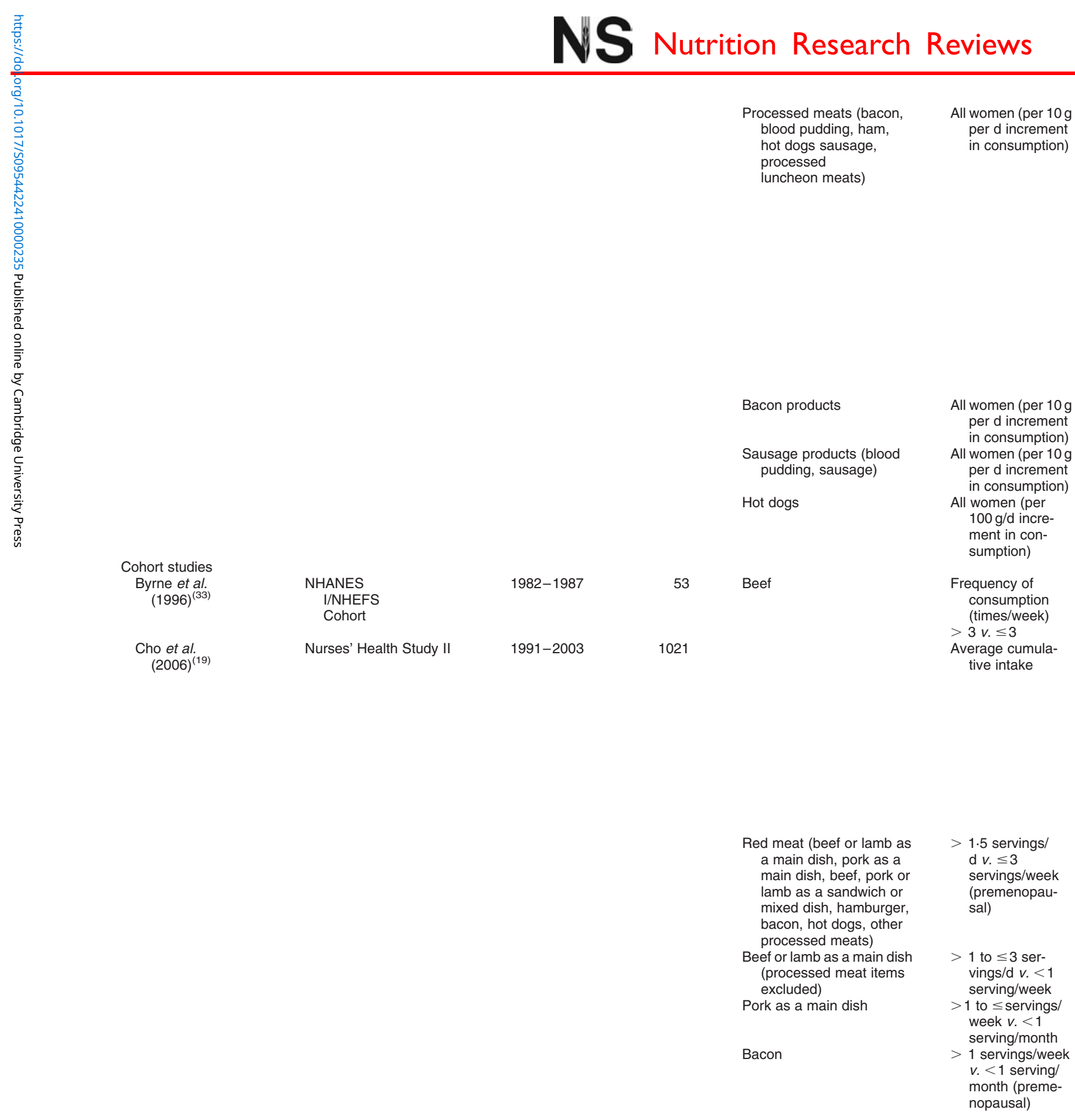

$0.98 \dagger$

$0.96,1.00$

ge at menarche

interaction between

parity and age at

first birth, oral

contraceptive use,

history of benign

breast disease,

family history of

breast cancer,

menopausal status,

BMl, interaction of

BMI and menopau-

sal status, postme-

use smoking status,

us, sation,

education, height,

energy intake

$0.89,1.09$

$0.83,1.07$

$0.39,1.44$

Age

Age, calendar year of interview, smoking, height, parity, age at at menarche, family history of breast cancer, history of benign breast contraceptive use, alcohol intake,

$0.96,1.67$ energy intake

$\begin{array}{lc}\text { a main dish, pork as a } & \mathrm{d} v . \leq 3 \\ \text { main dish, beef, pork or } & \text { servings/week } \\ \text { lamb as a sandwich or } & \text { (premenopau- } \\ \text { mixed dish, hamburger, } & \text { sal) } \\ \text { bacon, hot dogs, other } & \\ \text { processed meats) } & \\ \text { Beef or lamb as a main dish } & >1 \text { to } \leq 3 \text { ser- } \\ \text { (processed meat items } & \text { vings/d } v .<1 \\ \text { excluded) } & \text { serving/week } \\ \text { Pork as a main dish } & >1 \text { to } \leq \text { servings/ } \\ & \text { week } v .<1 \\ & \text { serving/month } \\ & 1 \text { servings/week } \\ & v .<1 \text { serving/ } \\ \text { month (preme- } & \text { nopausal) }\end{array}$




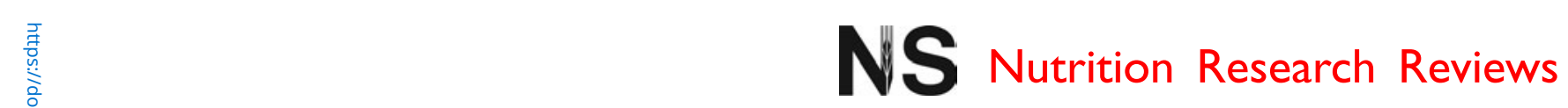

Table 1. Continued

\begin{tabular}{|c|c|c|c|c|c|c|c|c|}
\hline Author and year & Cohort & Follow-up & $\begin{array}{l}\text { Cases in } \\
\text { cohort }(n)\end{array}$ & $\begin{array}{c}\text { Definition of } \\
\text { exposure variable }\end{array}$ & $\begin{array}{l}\text { Analytical } \\
\text { comparison }\end{array}$ & $\begin{array}{l}\text { Relative risk } \\
\text { estimate }^{*}\end{array}$ & $95 \% \mathrm{Cl}$ & $\begin{array}{l}\text { Statistical } \\
\text { adjustment }\end{array}$ \\
\hline & & & & Hot dogs & $\begin{array}{c}>1 \text { servings } / \text { week } \\
v .<1 \text { serving/ } \\
\text { month (preme- } \\
\text { nopausal) }\end{array}$ & $1 \cdot 14 \dagger \ddagger$ & $0.83,1.57$ & \\
\hline & & & & $\begin{array}{l}\text { Other processed meats } \\
\text { (sausage, salami, } \\
\text { bologna) }\end{array}$ & $\begin{array}{c}>3 \text { servings/week } \\
v .<1 \text { serving/ } \\
\text { month (preme- } \\
\text { nopausal) }\end{array}$ & $1 \cdot 28 \dagger \ddagger$ & $0.87,1.88$ & \\
\hline \multirow[t]{2}{*}{$\begin{array}{l}\text { Cross et al. } \\
(2007)^{(11)}\end{array}$} & $\begin{array}{l}\text { NIH-AARP Diet and } \\
\text { Health Study }\end{array}$ & 1995-2003 & 5872 & $\begin{array}{l}\text { Red meat (beef, pork, } \\
\text { lamb, bacon, cold cuts, } \\
\text { ham, hamburger, hot } \\
\text { dogs, liver, pork sau- } \\
\text { sage, steak, meats } \\
\text { added to mixed foods } \\
\text { such as pizza, chili, } \\
\text { lasagna, and stew) }\end{array}$ & $\begin{array}{l}62.7 \mathrm{~g} / 1000 \mathrm{kcal} \\
\text { v. } 9.8\end{array}$ & $1.02 \dagger$ & $0.93,1.12$ & \multirow[t]{2}{*}{$\begin{array}{l}\text { Age, sex, education, } \\
\text { marital status, family } \\
\text { history of cancer, } \\
\text { race, BMI, smoking, } \\
\text { physical activity, } \\
\text { total energy intake, } \\
\text { alcohol intake, and } \\
\text { fruit and vegetable } \\
\text { consumption }\end{array}$} \\
\hline & & & & $\begin{array}{l}\text { Processed meat (bacon, } \\
\text { ham, red and white meat } \\
\text { (poultry) versions of: } \\
\text { sausage, luncheon } \\
\text { meats, cold cuts, hot } \\
\text { dogs; meats added to } \\
\text { mixed foods such as } \\
\text { pizza, chili, lasagna, and } \\
\text { stew) }\end{array}$ & $\begin{array}{c}22 \cdot 6 \mathrm{~g} / 1000 \mathrm{kcal} v . \\
1.6\end{array}$ & $1.03 \dagger$ & $0.94,1.12$ & \\
\hline \multirow[t]{3}{*}{$\begin{array}{l}\text { Egeberg et al. } \\
\quad(2008)^{(15)} \S\end{array}$} & $\begin{array}{l}\text { Diet, Cancer and } \\
\text { Health Cohort Study }\end{array}$ & $1993-2000$ & 378 & & $\begin{array}{l}\text { Quartiles of intake } \\
\text { (g/d), postme- } \\
\text { nopausal } \\
\text { women }\end{array}$ & & & \multirow[t]{3}{*}{$\begin{array}{l}\text { Parity, age at first birth } \\
\text { education, duration } \\
\text { of HRT, intake of } \\
\text { alcohol, and BMI }\end{array}$} \\
\hline & & & & $\begin{array}{l}\text { Red meat (beef, veal, pork, } \\
\text { lamb and offal) }\end{array}$ & $>80 v .<50$ & $1.65 \dagger$ & $1 \cdot 09,2 \cdot 50$ & \\
\hline & & & & $\begin{array}{l}\text { Processed meat (pro- } \\
\text { cessed red meat, } \\
\text { including bacon, } \\
\text { smoked ham, salami, } \\
\text { frankfurter, Cumberland } \\
\text { sausage, cold cuts, liver } \\
\text { pâté and processed fish } \\
\text { prepared by pickling, } \\
\text { salting, or smoking) }\end{array}$ & $>45$ v. $<20$ & $1.59 \dagger$ & $1 \cdot 02,2 \cdot 47$ & \\
\hline
\end{tabular}




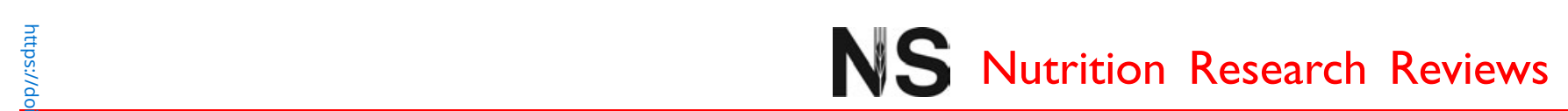
$\begin{array}{cc}\text { Ferrucci et al. } & \text { Prostate, Lung, Color- } \\ (2009)^{(14)} & \text { ectal, and Ovarian } \\ \text { Cancer Screening } & \text { Trial }\end{array}$

1993-2001
1980-1994

\section{Quintiles of intak (g/1000 kcal), postmenopau- sal women}

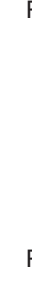

Red meat (bacon, beef, cheeseburd cuts, ham hamburgers cuts, ham, hamburgers, sausage, veal, venison, sausage, veal, venison, mixed dishes)

Processed meat (bacon, cold cuts, ham, hot dogs, and sausage) Red meat (hot dog, bacon processed meat, hamburger, beef, pork or lamb as a sandwich, pork as main dish, bee or lamb as main dish, meatloaf)

$\begin{array}{cc}\text { Red meat (beef, pork, or } & \text { Frequency of } \\ \text { lamb as a main dish, } & \text { consumption } \\ \text { hamburger, processed } & \text { (servings/d) } \\ \text { meat, bacon, hot dog) } & \end{array}$

52.8 v. 9.4

ER-positive/PRpositive tumours Adolescent diet: quintiles of intake (servings/d) (servings/d) meat, bacon, hot dog)

Age (continuous), race education, study centre, randomisation group, family history of breast cancer, age at menarche, age at menopause, age at ber of live births, ber of live births, history of benign breast disease, number of mammo3 years, menopau sal hormone therapy use, BMI, alcohol intake, total fat intake, and total iner

$1.23+$

$1.00,1.51$

energy intake

Age, time period, total energy intake, height, parity and at age 18 years, ag at menarche, family history of breast cancer, history of benign breast disstatus, alcohol intake, contraceptive use, weight gain since age 18 years
Matched: year of birth, menopausal status, month and time of blood draw, fasting status at blood draw, postmenopausal hormone use. Adjusted: age at menarche, parity, age at first birth,

BMI, family history

of breast cancer in

mother or sister, breast disease 


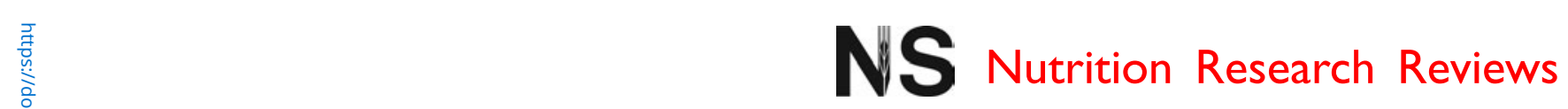

Table 1. Continued

\begin{tabular}{|c|c|c|c|}
\hline Author and year & Cohort & Follow-up & $\begin{array}{l}\text { Cases in } \\
\text { cohort }(n)\end{array}$ \\
\hline $\begin{array}{l}\text { Holmes et al. } \\
\quad(2003)^{(22)}\end{array}$ & Nurses' Health Study & $1980-1998$ & 2956 \\
\hline
\end{tabular}

\begin{tabular}{ll}
$\begin{array}{c}\text { Definition of } \\
\text { exposure variable }\end{array}$ & \multicolumn{1}{c}{$\begin{array}{c}\text { Analytical } \\
\text { comparison }\end{array}$} \\
Processed meat & $>1 v . \leq 0.5$ \\
Bacon & $>0.50 v . \leq 0.14$ \\
& $>0.07 v . \leq 0.07$ \\
& Quintiles of \\
cumulative \\
average intake \\
(servings/d)
\end{tabular}

Red meat

Hot dog

Bacon

Other processed meat dog, bacon, other processed meat)

\begin{tabular}{|c|c|c|}
\hline$\geq 1.32 v . \leq 0.55$ & 0.94 & $0.84,1.05$ \\
\hline $\begin{array}{l}\geq 1.32 \mathrm{v} . \leq 0.55 \\
\text { (premenopausal } \\
\text { women) }\end{array}$ & 0.94 & $0.72,1.22$ \\
\hline $\begin{aligned} & \geq 1.32 \mathrm{v} . \leq 0.55 \\
& \text { (postmenopausal } \\
& \text { women) }\end{aligned}$ & 0.99 & $0.86,1 \cdot 13$ \\
\hline $\begin{array}{l}\geq 0.46 \mathrm{v} . \leq 0.10 \\
\quad(\text { all women) }\end{array}$ & 0.94 & $0.85,1.05$ \\
\hline $\begin{array}{l}\geq 0.46 \mathrm{v} . \leq 0 \cdot 10 \\
\quad \text { (premenopausal } \\
\text { women) }\end{array}$ & 0.86 & $0.67,1.09$ \\
\hline $\begin{array}{l}\geq 0.46 \mathrm{v} . \leq 0.10 \\
\text { (postmenopausal } \\
\text { women) }\end{array}$ & $1 \cdot 0$ & $0.88,1.13$ \\
\hline $\begin{aligned} \geq 0.12 \mathrm{v} . \leq 0.01 \\
\quad(\text { all women) }\end{aligned}$ & 1.04 & $0.95,1.15$ \\
\hline $\begin{array}{l}\geq 0.12 \mathrm{v} . \leq 0.01 \\
\quad \text { (premenopausal } \\
\text { women) }\end{array}$ & $1 \cdot 16$ & $0.94,1.44$ \\
\hline $\begin{aligned} & \geq 0.12 \mathrm{v} . \leq 0.01 \\
& \text { (postmenopausal } \\
& \text { women) }\end{aligned}$ & 1.01 & $0.90,1.14$ \\
\hline $\begin{array}{l}\geq 0.14 \mathrm{v} .0 \\
\quad \text { (all women) }\end{array}$ & 0.96 & $0.87,1.07$ \\
\hline $\begin{aligned} \geq & 0.14 \mathrm{v} .0 \\
& \text { (premenopausal } \\
& \text { women) }\end{aligned}$ & 0.93 & $0.73,1.19$ \\
\hline $\begin{array}{l}\geq 0.14 \mathrm{v} .0 \\
\text { (postmenopausal } \\
\text { women) }\end{array}$ & 1.01 & $0.89,1.14$ \\
\hline$\geq 0.21 \mathrm{v} . \leq 0.02$ & 0.89 & $0.80,0.98$ \\
\hline
\end{tabular}

Statistical adjustment

$0 \cdot 6,1 \cdot 3$

$0.7,1.5$

$1.0,1.9$

Age, 2-year time

period, total energy intake, alcohol

intake, parity and

age at first birth, BM

at age 18 years,

weight change since

age 18 years,

height, family history

of breast cancer,

history of benign

breast disease, age

at menarche, meno-

pausal status, age

at menopause and

HRT use categories,

duration of meno-

pause 


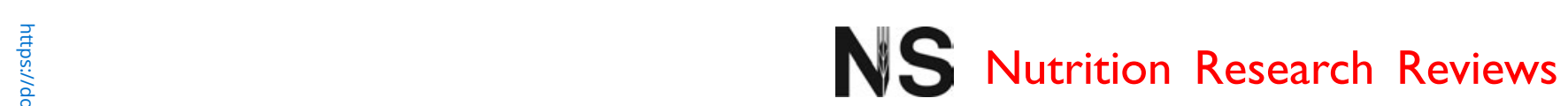

Kabat et al.

(same overall study

population as

Cross et al.
Larsson et al
$(2009)^{(12)}$

$(2006)^{(21)}$
NIH-AARP Diet and Health Study

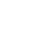

1995-2003

3818

Swedish Mammography Cohort

1987-2007

2952

Red meat

Processed meat

otal red meat (sum of

processed meat)
$>43.7 v . \leq 13.0$
$>12.5$ v. $\leq 2.2$
Quintiles of
intake $\geq 98 \mathrm{~g} / \mathrm{d}$
v. $<46$

Total cases

$\mathrm{ER}+/ \mathrm{PR}+$

tumours

$\mathrm{ER}+/ \mathrm{PR}-$

tumours

tumours

Fresh red meat (all fresh and minced pork, beef and veal)

Processed meat (ham, bacon, sausages, salami, processed meat

cuts, liver pâté, and
blood sausages)

Nurses' Health Study,
Nurses' Health

1976

Nurses' Health

(Nurses' Health

Study I), 1989

(Nurses' Health

Study II) -1993
582
0.71

women)

$0.21 \mathrm{v} . \leq 0.02$
(postmenopausa women)

Quintiles of intake

postmenopausal

pon
$0.57,0.88$

$0.85,1.08$

Age, energy intake, meat groups, age at entry, BMl, age at menarche, age at first live birth, family cancer, HRT, educancer, HRT, education, race, satualcohol intake,

physical activity

physical activity,

menopause, num-

ber of breast biop-

sies, and height

$0.93,1 \cdot 18$

$0.90,1.12$ year of question-

naire cycle; adjuste

for education, BMI,

height, parity, age at

first birth, age at

menarche, age at

menopause, use of

oral contraceptives,

use of postmeno-

pausal hormones,

family history of

breast cancer,

intakes of total

energy and alcohol

$0.86,1.12$
$0.90,1.34$

$0.60,1.23$

.

$0.70,1.79$

$0.79,1.03$

Quintiles of intake

$1.08 \dagger$

$0.96,1.22$

Pre-school diet: per unit increase

Servings/d

(consumed at pre-school age)
Year of birth, age at menarche, parity, age at first birth, family history of breast cancer, adult BM 


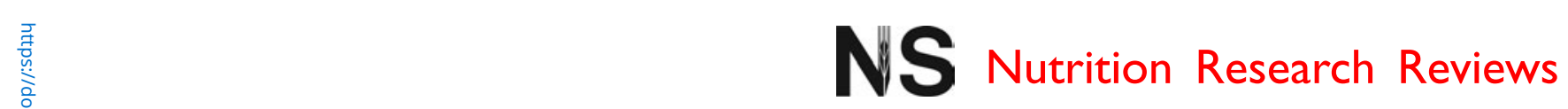

Table 1. Continued

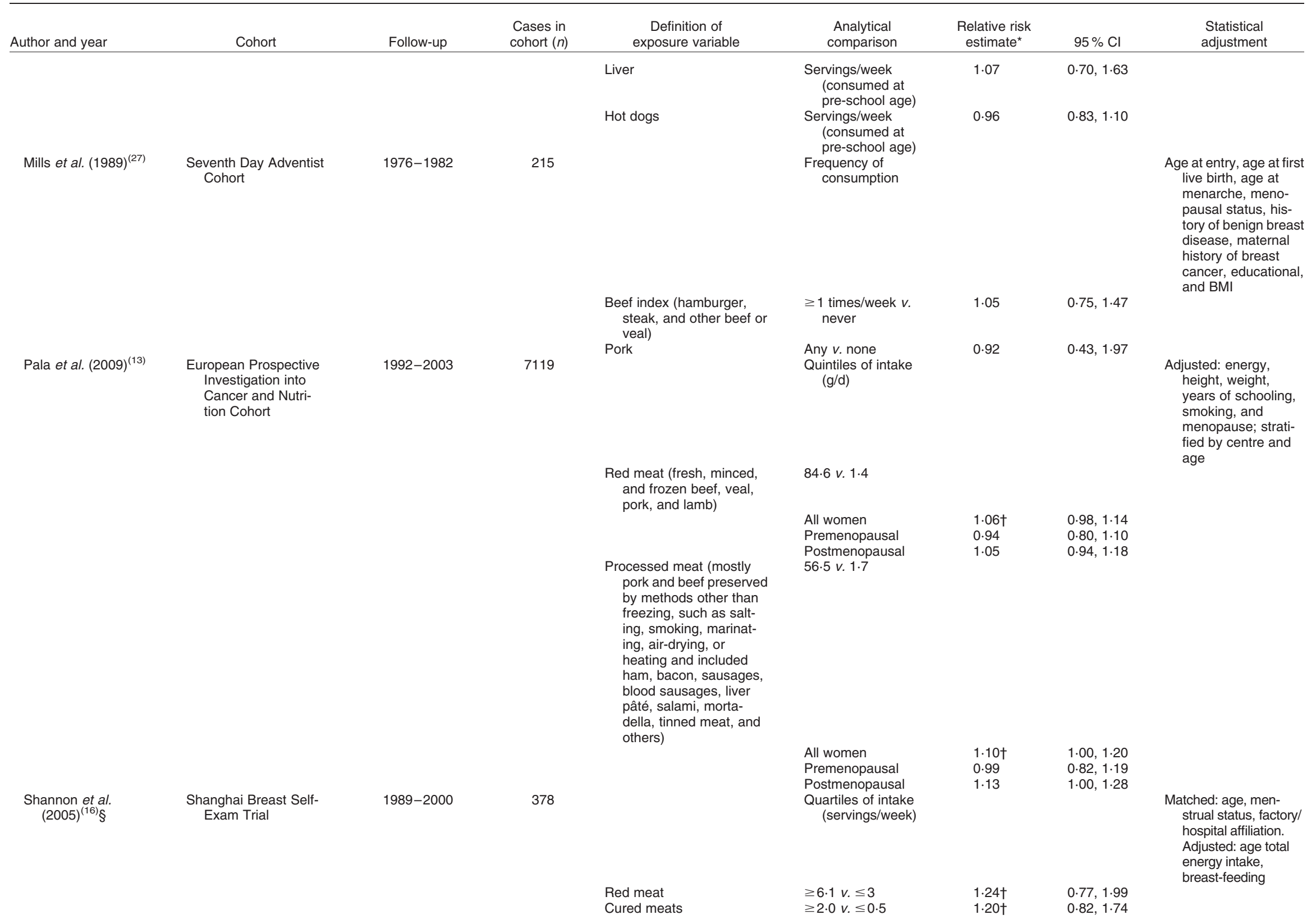




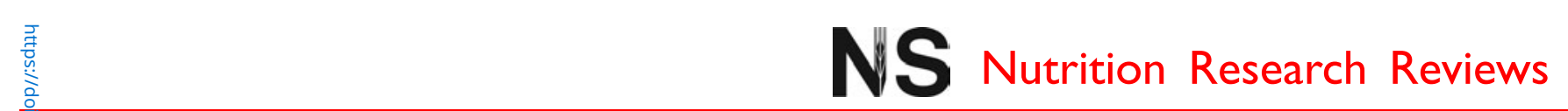

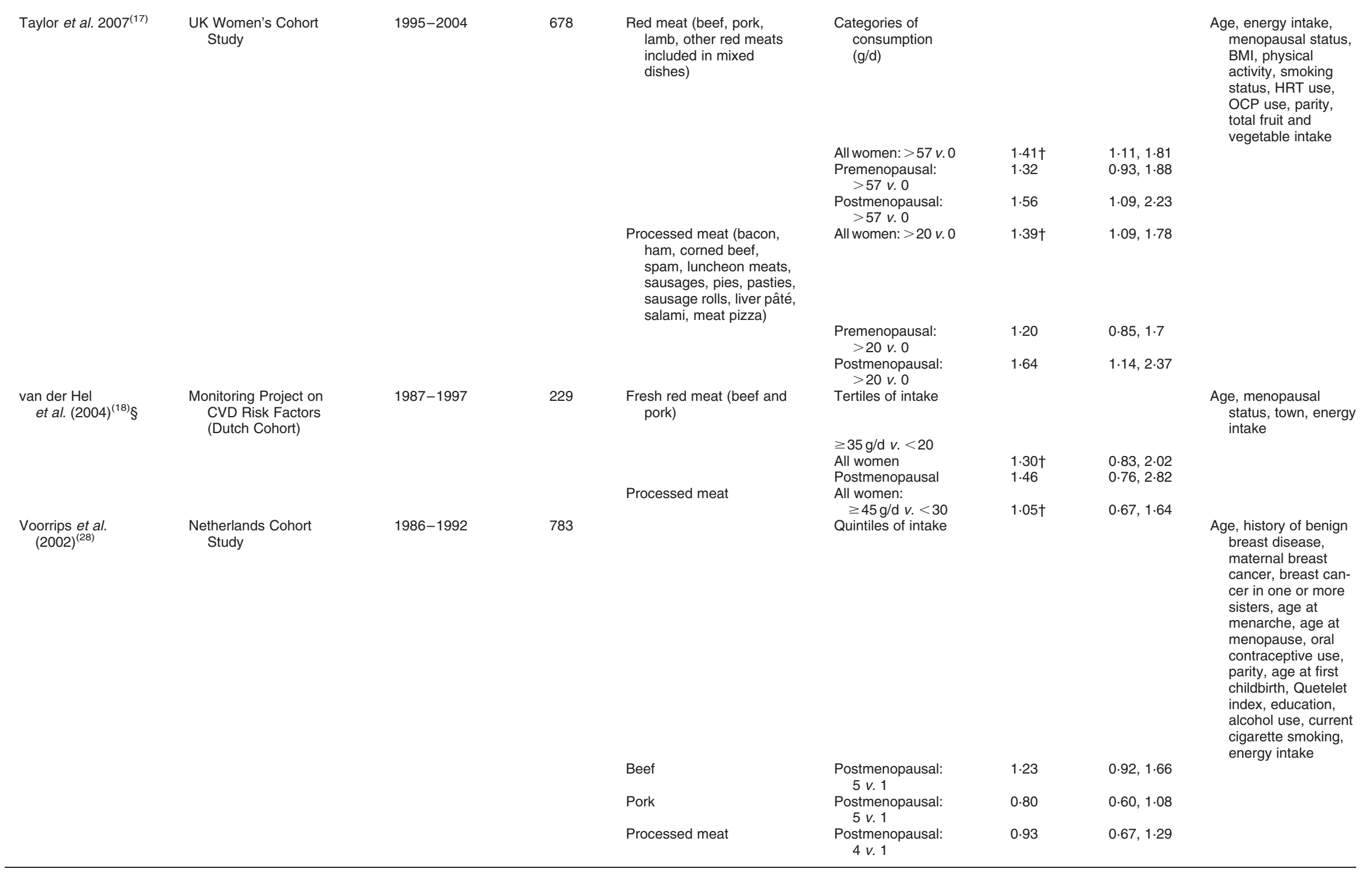

NHANES, National Health and Nutrition Examination Survey; NHEFS, NHANES I Epidemiologic Follow-up Study; HRT, hormone replacement therapy; ER, oestrogen receptor; PR, progesterone receptor; OCP, oral contraceptive pill.

Highest $v$. lowest intake comparison unless otherwise noted.

† Data points are those used in the primary meta-analyses, presented in Figs. 1 and 2.

$¥$ Risk estimates combined using fixed-effects model before inclusion in primary meta-analysis.

$\S$ Nested case-control study. 


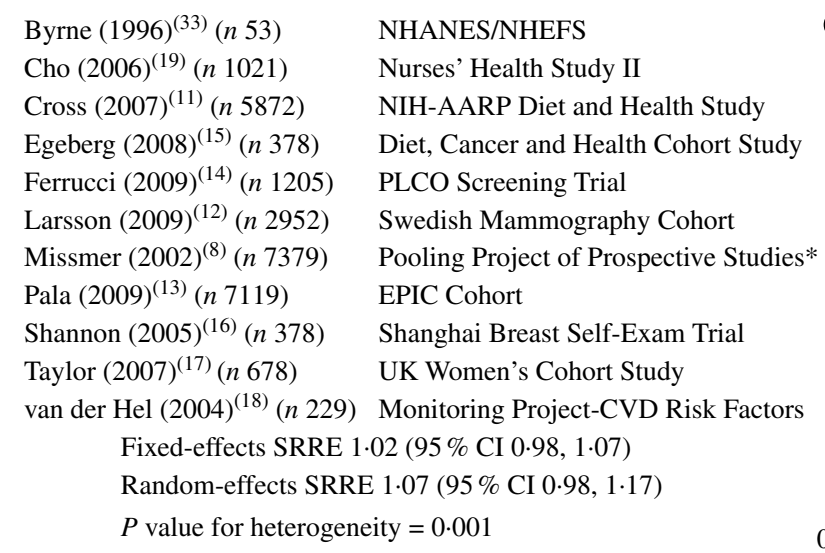

Sensitivity analysis: Larsson et al. (2009) ${ }^{(12)}$ removed due to partial overlap with Missmer et al. $(2002)^{(8)}$

Fixed-effects SRRE 1.04 (95\% CI 0.99, 1.08)

Random-effects SRRE 1.10 (95\% CI 1.00, 1.21)

Fig. 1. Meta-analysis of prospective studies of red meat and breast cancer. * Includes data pooled from eight cohorts; partial overlap with Larsson et al. $(2009)^{(12)}$. RR, relative risk; NHANES, National Health and Nutrition Examination Survey; NHEFS, NHANES I Epidemiologic Follow-up Study; PLCO, Prostate, Lung, Colorectal, and Ovarian; EPIC, European Prospective Investigation into Cancer and Nutrition; SRRE, summary relative risk estimate.

provided only $22 \%$ of the total weight to the Pooling Project data from Missmer et al. ${ }^{(8)}$ (which included eight cohorts) and $78 \%$ of the relative weight to the five additional studies in this model. The fixed-effects model more appropriately provided $58 \%$ of the relative weight to Missmer et al. ${ }^{(8)}$.

\section{Processed meat}

No association was observed in the fixed-effects metaanalysis of processed meat intake and breast cancer (SRRE $1.00 ; 95 \%$ CI $0.98,1.01 ; P$ value for heterogeneity $=0.005$ ) (Table 2; Fig. 2). This model provided $85 \%$ of the relative weight to data from the Pooling Project analysis (seven cohorts). In contrast, the random-effects model provided only $23 \%$ of relative weight to this study, resulting in a slightly greater summary association (SRRE $1.08 ; 95 \%$ CI 1.01, 1.16). The Pooling Project data represented a $10 \%$ increment of processed meat intake rather than a 'high' intake quantile. Removal of data from this study, and inclusion of data from individual publications of the Netherlands Cohort study ${ }^{(28)}$ and the Nurses' Health Study ${ }^{(22)}$, both of which analysed study populations included in the publication by Missmer et al. ${ }^{(8)}$, resulted in summary associations of $1.06(95 \%$ CI $1.01,1.11)$ and $1.07(95 \%$ CI 1.01, 1.14) for fixed- and random-effects models, respectively. Meta-analysis of four studies that reported data for premenopausal women resulted in an SRRE of 1.01 (95\% CI 0.90, 1.13) (same result for fixed and random effects) (Table 2). The summary association was slightly greater among the seven studies that reported data for postmenopausal women (fixed-effects SRRE 1.06; $95 \%$ CI $1.00,1.13 ; P$ value for heterogeneity $=0.051$; randomeffects SRRE 1.09; $95 \%$ CI 0.99, 1.21) (Table 2).
The SRRE for each $30 \mathrm{~g}$ increment of processed meat intake was $1.03(95 \%$ CI $1.00,1.06 ; P$ value for heterogeneity $<0.0001)$ in the fixed-effects model and $1.06(95 \%$ CI $0.99,1.14)$ in the random-effects model. Among premenopausal women, the summary association for each $30 \mathrm{~g}$ increment of processed meat was 1.03 (95\% CI 0.98, 1.08; fixed effects) with a non-significant $P$ value for heterogeneity $(P=0.535)$. Among postmenopausal women, the fixed-effects and random-effects SRRE for each $30 \mathrm{~g}$ increment of processed meat intake were 1.07 (95\% CI $1.02,1.13 ; P$ value for heterogeneity $<0.0001)$ and 1.13 (95\% CI $0.99,1.28)$, respectively.

Two studies ${ }^{(19,22)}$ of the Nurses' Health Study I and II cohorts reported categorical intake data for hot dogs, bacon and other processed meat (sausage, salami, bologna), and one study ${ }^{(14)}$ reported data for bacon and sausage. Metaanalysis of the highest $v$. lowest intake of bacon resulted in an SRRE of $1.01(95 \%$ CI $0.92,1.12 ; P$ value for heterogeneity $=0.752$ ), and the SRRE for hot dogs was $1.05(95 \%$ CI $0.96,1.15 ; P$ value for heterogeneity $=0.589)$ (data not shown). In the meta-analysis of intake of other processed meat, the SRRE was 1.16 (95\% CI 0.98, 1.39). Similarly, non-significant associations were reported for each $10 \mathrm{~g} / \mathrm{d}$ increment of bacon (pooled RR 0.99; $95 \% \mathrm{CI}$ $0.89,1.09$ ) and sausage (pooled RR 0.94; $95 \%$ CI 0.83 , 1.07) in the Pooling Project ${ }^{(8)}$ analysis of seven cohorts. In addition, an inverse association for each $100 \mathrm{~g} / \mathrm{d}$ increment of hot dogs was observed (pooled RR 0.75; $95 \%$ CI $0.39,1.44)^{(8)}$.

\section{Publication bias}

In the assessment of prospective studies of red meat intake and breast cancer, the point estimates were skewed slightly 
Table 2. Summary of meta-analysis results of red meat and processed meat and breast cancer

\begin{tabular}{|c|c|c|c|}
\hline Model & SRRE & $95 \% \mathrm{Cl}$ & Relevant notes \\
\hline \multicolumn{4}{|l|}{ Red meat } \\
\hline Overall (high intake $v$. low intake) - fixed effects & 1.02 & $0.98,1.07$ & $\begin{array}{l}\text { Includes data reported in the Pooling Project publication (Missmer et al. }(2002)^{(8)} \text { ) and ten } \\
\text { additional prospective studies }\end{array}$ \\
\hline Overall (high intake $v$. low intake) - random effects & 1.07 & $0.98,1 \cdot 17$ & $\begin{array}{l}\text { Includes data reported in the Pooling Project publication (Missmer et al. }(2002)^{(8)} \text { ) and ten } \\
\text { additional prospective studies }\end{array}$ \\
\hline Independent publications - fixed effects & 1.03 & $0.99,1.08$ & Includes thirteen prospective studies, data from Pooling Project excluded \\
\hline Independent publications - random effects & 1.06 & $0.98,1.15$ & Includes thirteen prospective studies, data from Pooling Project excluded \\
\hline Studies published between 2003 and 2007 - fixed effects & 1.04 & $1.00,1.09$ & Includes ten prospective studies (published after the Pooling Project) \\
\hline Studies published between 2003 and 2007 - random effects & 1.08 & $0.99,1.18$ & Includes ten prospective studies (published after the Pooling Project) \\
\hline Premenopausal $^{*}$ & 1.02 & $0.92,1.13$ & $\begin{array}{l}\text { Data from Pala et al. }(2009)^{(13)} \text {, Taylor et al. }(2007)^{(17)} \text {, Cho et al. }(2006)^{(19)} \text {, Missmer et al. } \\
(2002)\end{array}$ \\
\hline Postmenopausal - fixed effects & 1.02 & $0.98,1.08$ & $\begin{array}{l}\text { Data from Pala et al. }(2009)^{(13)} \text {, Ferrucci et al. }(2009)^{(14)} \text {, Kabat et al. }(2009)^{(10)} \text {, Egeberg } \\
\text { et al. }(2008)^{(15)} \text {, Taylor et al. }(2007)^{(17)} \text {, Missmer et al. }(2002)^{(8)}\end{array}$ \\
\hline Postmenopausal - random effects & $1 \cdot 11$ & $0.99,1 \cdot 25$ & $\begin{array}{l}\text { Data from Pala et al. }(2009)^{(13)} \text {, Ferrucci et al. }(2009)^{(14)} \text {, Kabat et al. }(2009)^{(10)} \text {, Egeberg } \\
\text { et al. }(2008)^{(15)} \text {, Taylor et al. }(2007)^{(17)} \text {, Missmer et al. }(2002)^{(8)}\end{array}$ \\
\hline Dose-response: $100 \mathrm{~g}$ increment - fixed effects & 1.04 & $1.00,1.07$ & Includes data from the Pooling Project publication and eight additional prospective studies \\
\hline Dose-response: $100 \mathrm{~g}$ increment - random effects & 1.12 & $1.03,1.23$ & Includes data from the Pooling Project publication and eight additional prospective studies \\
\hline Premenopausal*: $100 \mathrm{~g} / \mathrm{d}$ increment & 1.01 & $0.92,1 \cdot 11$ & $\begin{array}{l}\text { Data from Pala et al. }(2009)^{(13)} \text {, Taylor et al. }(2007)^{(17)} \text {, Cho et al. }(2006)^{(19)} \text {, Missmer et al. }\end{array}$ \\
\hline Postmenopausal: dose-response $100 \mathrm{~g}$ increment - fixed effects & 1.03 & $0.98,1.08$ & $\begin{array}{l}\text { Data from Pala et al. }(2009)^{(13)} \text {, Kabat et al. }(2009)^{(10)} \text {, Ferrucci et al. }(2009)^{(14)} \text {, Egeberg } \\
\text { et al. }(2008)^{(15)} \text {, Taylor et al. }(2007)^{(17)} \text {, Missmer et al. }(2002)^{(8)}\end{array}$ \\
\hline Postmenopausal: dose-response $100 \mathrm{~g}$ increment - random effects & $1 \cdot 22$ & $1.04,1.44$ & $\begin{array}{l}\text { Data from Pala et al. }(2009)^{(13)} \text {, Kabat et al. (2009) }{ }^{(10)} \text {, Ferrucci et al. }(2009)^{(14)} \text {, Egeberg } \\
\text { et al. }(2008)^{(15)} \text {, Taylor et al. }(2007)^{(17)} \text {, Missmer et al. }(2002)^{(8)}\end{array}$ \\
\hline \multicolumn{4}{|r|}{ 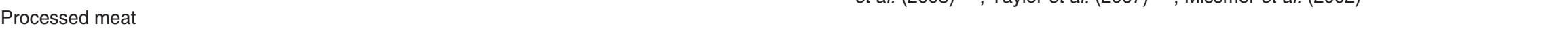 } \\
\hline Overall (high intake $v$. low intake) - fixed effects & 1.00 & $0.98,1.01$ & $\begin{array}{l}\text { Includes data reported in the Pooling Project publication and nine additional prospective } \\
\text { studies }\end{array}$ \\
\hline Overall (high intake $v$. low intake) - random effects & 1.08 & $1 \cdot 01,1 \cdot 16$ & $\begin{array}{l}\text { Includes data reported in the Pooling Project publication and nine additional prospective } \\
\text { studies }\end{array}$ \\
\hline Independent publications ${ }^{*}$ & 1.06 & $1.01,1.11$ & Includes eleven prospective studies, data from Pooling Project excluded \\
\hline Premenopausal $^{*}$ & 1.01 & $0.90,1 \cdot 13$ & $\begin{array}{l}\text { Data from Pala et al. }(2009)^{(13)} \text {, Taylor et al. }(2007)^{(17)} \text {, Cho et al. }(2006)^{(19)} \text {, Holmes et al. } \\
(2003)^{(22)}\end{array}$ \\
\hline Postmenopausal - fixed effects & 1.06 & $1 \cdot 00,1 \cdot 13$ & $\begin{array}{l}\text { Data from Pala et al. }(2009)^{(13)} \text {, Ferrucci et al. }(2009)^{(14)}, \text { Kabat } \text { et al. }(2009)^{(10)} \text {, Egeberg } \\
\text { et al. }(2008)^{(15)} \text {, Taylor et al. }(2007)^{(17)} \text {, Holmes et al. }(2003)^{(22)} \text {, Voorrips et al. }(2002)^{(28)}\end{array}$ \\
\hline Postmenopausal - random effects & 1.09 & $0.99,1 \cdot 21$ & $\begin{array}{l}\text { Data from Pala et al. }(2009)^{(13)} \text {, Ferrucci et al. }(2009)^{(14)}, \text { Kabat }^{(2)} \text { al. }(2009)^{(10)} \text {, Egeberg } \\
\text { et al. }(2008)^{(15)} \text {, Taylor et al. }(2007)^{(17)} \text {, Holmes et al. }(2003)^{(22)} \text {, Voorrips et al. }(2002)^{(28)}\end{array}$ \\
\hline Dose-response: $30 \mathrm{~g}$ increment - fixed effects & 1.03 & $1.00,1.06$ & $\begin{array}{l}\text { Includes data from the Pooling Project publication and seven additional prospective } \\
\text { studies }\end{array}$ \\
\hline Dose-response: $30 \mathrm{~g}$ increment - random effects & 1.06 & $0.99,1.14$ & $\begin{array}{l}\text { Includes data from the Pooling Project publication and seven additional prospective } \\
\text { studies }\end{array}$ \\
\hline Premenopausal*: $30 \mathrm{~g} / \mathrm{d}$ increment & 1.03 & $0.98,1.08$ & $\begin{array}{l}\text { Data from Pala et al. }(2009)^{(13)} \text {, Taylor et al. }(2007)^{(17)} \text {, Cho et al. }(2006)^{(19)} \text {, Holmes et al. } \\
(2003)^{(22)}\end{array}$ \\
\hline Postmenopausal: dose-response $30 \mathrm{~g}$ increment - fixed effects & 1.07 & $1 \cdot 02,1 \cdot 13$ & 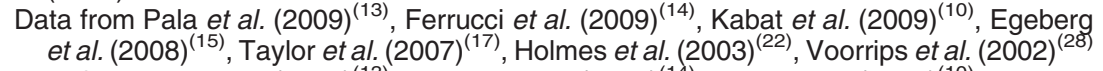 \\
\hline Postmenopausal: dose-response $30 \mathrm{~g}$ increment - random effects & $1 \cdot 13$ & $0.99,1 \cdot 28$ & $\begin{array}{l}\text { Data from Pala et al. }(2009)^{(13)} \text {, Ferrucci et al. }(2009)^{(14)},{\text { Kabat et al. }(2009)^{(10)} \text {, Egeberg }} \text { et al. }(2008)^{(15)} \text {, Taylor et al. }(2007)^{(17)} \text {, Holmes et al. }(2003)^{(22)} \text {, Voorrips et al. }(2002)^{(28)}\end{array}$ \\
\hline
\end{tabular}

SSRE, summary relative risk estimate.

${ }^{*}$ Fixed-effects model; results similar for random effects. 


\begin{tabular}{ll} 
First author and year & Cohort \\
Cho $(2006)^{(19)}(n$ 1021) & Nurses' Health Study II \\
Cross $(2007)^{(11)}(n$ 5872) & NIH-AARP Diet and Health Study \\
Egeberg $(2008)^{(15)}(n$ 378) & Diet, Cancer and Health Cohort Study \\
Ferrucci $(2009)^{(14)}(n$ 1205) & PLCO Screening Trial \\
Larsson $(2009)^{(12)}(n$ 2952) & Swedish Mammography Cohort \\
Missmer $(2002)^{(8)}(n$ 7379) & Pooling Project of Prospective Studies* \\
Pala $(2009)^{(13)}($ all $)(7119)$ & EPIC Cohort \\
Shannon $(2005)^{(16)}(n$ 378) & Shanghai Breast Self-Exam Trial \\
Taylor $(2007)^{(17)}(n$ 678) & UK Women's Cohort Study \\
van der Hel $(2004)^{(18)}(n$ 229) & Monitoring Project-CVD Risk Factors \\
\multicolumn{2}{c}{ Fixed-effects SRRE 1.00 (95\% CI 0.98, 1.01) } \\
Random-effects SRRE 1.08 (95\% CI 1.01, 1.16) \\
$P$ value for heterogeneity $=0 \cdot 005$
\end{tabular}

$0 \cdot 5$

Fig. 2. Meta-analysis of prospective studies of processed meat and breast cancer. * Includes data pooled from seven cohorts; partial overlap with
Larsson et al. $(2009)^{(12)}$. RR, relative risk; PLCO, Prostate, Lung, Colorectal, and Ovarian; EPIC, European Prospective Investigation into Cancer and Nutrition; SRRE, summary relative risk estimate.

to the right of the weighted effect size, indicating potential publication bias (Fig. 3). Using Duval and Tweedie's trim and fill method, in which the summary association is recomputed based on the imputation of potentially missing studies, resulted in changing the SRRE from 1.02 to 1.01 and from 1.07 to 1.01 for the fixed- and random-effects models, respectively (based on imputing three studies). Six studies were imputed for the processed meat analysis, resulting in changing the SRRE from 1.08 (95\% CI 1.01, $1.16)$ to 1.00 (95\% CI $0.94,1.06)$ based on the randomeffects model (note: the SRRE was virtually unchanged for the fixed-effects model).

\section{Discussion}

Since the publication of the Pooling Project analysis of eight cohorts in $2002^{(8)}$, several large prospective studies have been published that evaluated the relationship between red meat and processed meat consumption and breast cancer. Therefore, the objectives of our quantitative assessment were to synthesise and summarise data across all available prospective studies to update the state of the science, to better clarify any associations, and to identify potential sources of heterogeneity. Overall, most associations across the variety of meta-analysis models were slightly above the null value (i.e. 1.0) and not statistically significant. Significant heterogeneity was evident in most meta-analysis models, and the heterogeneity did not appear to be explained by menopausal status or by year of publication. Moreover, adjusting for publication bias resulted in attenuating summary associations.

In this quantitative assessment, data for red meat intake and breast cancer from ten prospective studies were combined with pooled data reported in the Pooling Project publication $^{(8)}$. Thus, we were able to meta-analyse data on over 25000 cases of breast cancer. Among all women, no statistically significant associations were observed in the high $v$. low red meat intake analyses, with SRRE of 1.02 and 1.07 for the fixed- and random-effects models, respectively. Although these summary associations were not indicative of a significant increased risk of breast cancer among consumers of red meat, significant heterogeneity was observed between the effect estimates in this analysis. The heterogeneity did not seem to be explained by selection of cohort data, as removal of data from the Pooling Project study did not modify the summary associations nor did analysing data from studies published after the Pooling Project. Moreover, fixed-effects summary associations were identical (i.e. 1.02) in the analyses of premenopausal women and postmenopausal women. Therefore, the heterogeneity in effect sizes is not probably due to variability in associations by menopausal status.

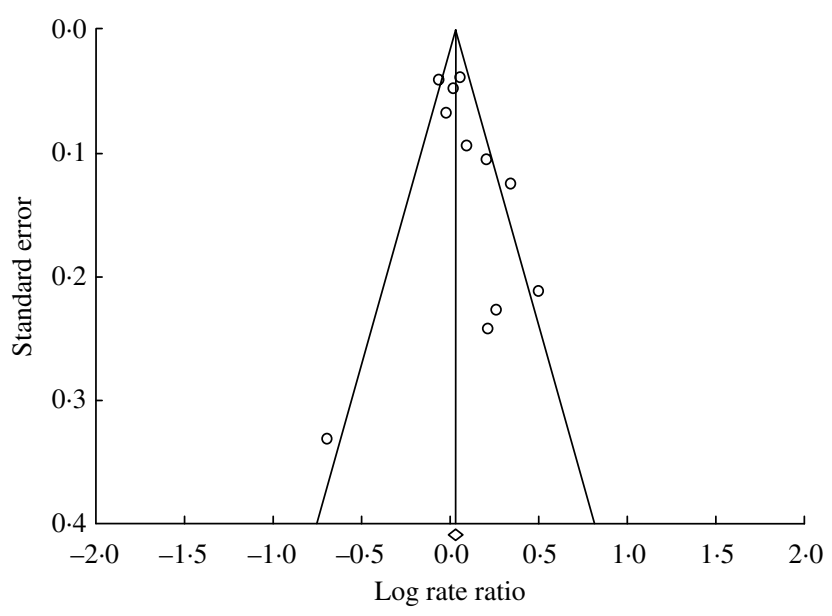

Fig. 3. Funnel plot for prospective studies of red meat and breast cancer. For studies, see Fig. 1. 
High $v$. low intake meta-analysis only takes into account the highest level of intake (compared with the referent group) as reported in a particular study, and the data for the middle intake categories are not typically analysed. In contrast, categorical dose-response regression metaanalysis utilises all available data for each intake strata to produce a summary estimate reflecting risk per incremental level of intake. Although this type of analysis uses all available data, it is assumed that risk increases (or decreases) linearly, and risk may be extrapolated to intake levels considerably higher than what is reported in an individual study. Indeed, we used $100 \mathrm{~g}$ increments in the meta-analyses of red meat intake to be consistent with the level reported in the Pooling Project analysis even though this intake level is generally higher than the reported intakes in the majority of cohorts. Similar to the high $v$. low intake analyses, summary associations for each $100 \mathrm{~g}$ increment of red meat intake were weakly elevated, but significant heterogeneity was observed (Table 2). Dose-response summary associations by menopausal status were similar for the fixed-effects meta-analyses, but the random-effects summary association was modestly stronger $(\mathrm{SRRE}=1.22)$ among postmenopausal women. This difference was due to less relative weight given to the Pooling Project data of eight cohorts and more weight given to the five other studies. In the Pooling Project analysis, the pooled RR for each $100 \mathrm{~g}$ increment of red meat across eight cohorts was 0.97. In contrast, the summary association across five studies of postmenopausal women published after the Pooling Project was 1.13 and 1.34 for the fixed-and random-effects models, respectively, although significant heterogeneity remained (sensitivity analysis data not shown).

Meta-analyses of processed meat intake and breast cancer were similar to the analyses of red meat. Summary associations ranged between 1.00 and 1.13 and most were not statistically significant. Among all women, no association was observed in the fixed-effects analysis of high $v$. low intake, while a summary association of 1.08 was observed in the random-effects model. This difference was largely due to less relative weight provided to the Pooling Project data. When data from the Pooling Project were excluded, the fixed- (i.e. 1.06) and random- (i.e. 1.07) effects models produced similar summary associations, although significant heterogeneity was observed. Summary associations were slightly stronger, albeit weakly elevated, in the analyses of postmenopausal women compared with premenopausal women; however, the CI were largely overlapped. Although data were relatively sparse, analyses of individual processed meat items (for example, bacon, hot dogs) were not supportive of significant associations with breast cancer.

Statistically, based on the available epidemiological data, we were unable to identify significant sources of heterogeneity, although between-study variability was present in most meta-analysis models. From a methodological standpoint, regardless of statistical heterogeneity, variability can be produced by a wide array of factors, such as the type of study population, the methods of dietary assessment and/or measurement, variable definitions (for example, food groups, serving sizes), analytical categorisations (for example, servings per week, g per d), exposure contrasts (analytical cut-points and comparisons of intake levels), and degree of adjustment for potential confounding factors. Despite these sources of potential variability, collectively, the meta-analyses produced relatively consistent results, with most summary associations just above the null value.

Although we were able to conduct a wide variety of metaanalyses for red/processed meat intake and breast cancer, data are relatively sparse for some emerging hypotheses. Indeed, how and/or whether diet early in life may contribute to the development of adult cancer is of increasing scientific interest. Of particular relevance is breast cancer because of increased mammary susceptibility to potential carcinogens during adolescence and early life ${ }^{(34)}$. In a case-control study nested within the Nurses' Health Study I and II cohorts, Michels et al. ${ }^{(21)}$ examined the potential effects of pre-school diet on subsequent breast cancer risk later in life. The mothers of participants in the Nurses' Health Study cohorts were asked about their daughters' perinatal and early childhood dietary habits using a thirty-food item questionnaire. Ground beef was associated with a nonsignificant $44 \%$ increased risk of breast cancer, while consumption of meat (as a main dish or as a sandwich or mixed dish) or hot dogs were associated inversely, albeit non-significantly, with subsequent breast cancer risk. In a study of the Nurses' Health Study II cohort ${ }^{(20)}$, participants were asked to complete a questionnaire regarding diet during high school, a life period that may be affected by micronutrient intake during adolescent growth. A nonsignificant positive association between the highest intake of red meat and subsequent risk of breast cancer was reported (RR 1.22; 95\% CI 0.82, 1.82), but no trend based on incremental intake was observed $(P$ value for trend $=0 \cdot 17)$. Interpretation of these studies should be made with some reservation, as results may be subject to poor recall since study participants (or mothers of cases) are reporting dietary habits that probably occurred $30-40$ or more years before ascertainment. Although an intriguing area of research, no conclusions at the present time can be drawn regarding the possible association between pre-school or adolescent meat consumption and adult breast cancer risk because of limited data.

Another area of increasing scientific interest is the potential relationship between dietary factors and breast cancer risk according to tumour hormone receptor status. Although breast tumours differ clinically and biologically by hormone receptor status ${ }^{(19)}$, there is little evidence regarding the potential association between red/processed meat and hormone receptor status cancer. In an analysis of the Nurses' Health Study II, Cho et al. ${ }^{(19)}$ evaluated whether the association between red meat or processed meat and breast cancer differed by hormone receptor status among premenopausal women. As reported earlier, the authors found a non-significant positive association between the highest intake quintile of red meat and total breast cancer (RR 1.27; 95\% CI 0.96, 1.67). The positive association, however, was restricted to women with hormone receptor-positive cancer (oestrogen receptor $(\mathrm{ER})+/$ progesterone receptor $(\mathrm{PR})+$ ) (RR $1.97 ; 95 \%$ CI $1.35,2 \cdot 88)$. A non-significant inverse association was reported among women with hormone receptor-negative 
cancer $(\mathrm{ER}-/ \mathrm{PR}-)$ (RR 0.89; $95 \%$ CI $0.43,1.84)$. Positive associations were also reported for pork (as a main dish), hamburger, bacon, hot dogs, and other processed meats (for example, sausage, salami, bologna) among women with $\mathrm{ER}+/ \mathrm{PR}+$ cancer, while inverse associations for these same meat groups were observed among women with ER - /PR - cancer. In contrast, in a recent analysis of the Swedish Mammography Cohort ${ }^{(12)}$, stronger associations for red meat intake were found among women with ER - /PR - cancer (RR 1.12; $95 \%$ CI 0.70, 1.79) than $\mathrm{ER}+/ \mathrm{PR}+$ cancer (RR $1.10 ; 95 \%$ CI $0.90,1 \cdot 34$ ). An inverse association for the highest red meat intake category was reported among women with ER $+/ \mathrm{PR}-$ cancer (RR 0.86; $95 \%$ CI 0.60, 1.23).

It has been hypothesised that mutagenic by-products, such as heterocyclic amines or polycyclic aromatic hydrocarbons, of cooking meat may contribute to mammary carcinogenesis. However, findings from epidemiological studies of heterocyclic amines and polycyclic aromatic hydrocarbons and breast cancer have been variable and limited to few investigations ${ }^{(10,14,35-38)}$. Some studies $^{(14,39-41)}$ have shown that consumption of well-done meat is associated positively with increasing the risk of breast cancer, but other studies ${ }^{(10,26,38)}$ have found no such effect. In a recent prospective analysis of 3818 postmenopausal breast cancer cases in the NIH-AARP Diet and Health Study cohort, no associations were found for meat cooked at high temperatures, well/very well-done cooked meat, overall mutagenic activity, or specific heterocyclic amines, and the authors concluded that their analysis 'provides no support for a role of meat mutagens in the development of postmenopausal breast cancer $^{(10)}$. In another recent analysis of postmenopausal women ${ }^{(14)}$, no significant associations were reported for well/very well-done cooked meat or overall mutagenic activity, but a significant positive association was found for 2-amino-3, 8-dimethylimidazo[4,5-f]quinoxaline (MeIQx). No linear trend was observed for MeIQx, however.

The relationship between meat consumption and breast cancer has been the focus of several epidemiological investigations, yet there has been no clear scientific consensus as to whether red or processed meat intake increases the risk of breast cancer. The current quantitative assessment summarises prospective data on over 25000 cases of breast cancer, and incorporates data from several recently published cohorts. The results of this meta-analysis do not appear to support an independent association between red meat or processed meat intake and breast cancer. Collectively, all summary associations were weakly elevated, with most ranging between 1.00 and 1.10. Some analyses produced statistically significant associations, although results were sensitive to the choice of model (fixed effects $v$. random effects). Heterogeneity was evident in most meta-analysis models, and this between-study variability could not be explained by analyses of menopausal status, year of publication, or inclusion/exclusion of specific cohorts. In addition, there was modest evidence of publication bias which may have skewed the summary associations slightly in the positive direction. Breast cancer is a heterogeneous disease with differing aetiologies; thus, the potential role that diet may play in the development of breast cancer among subgroups is of great public health importance. Recent studies have suggested that meat consumption may affect breast cancer risk through hormone receptor status, and that diet early in life may influence adult breast cancer. Data for these hypotheses are limited, however, and additional prospective studies are needed before conclusions can be drawn.

\section{Acknowledgements}

The present review received no specific grant from any funding agency in the public, commercial or not-for-profit sectors. The present study was partially supported by the Cattlemen's Beef Board, through the National Cattlemen's Beef Association (NCBA); and the National Pork Board. NCBA and the National Pork Board did not contribute to the writing, analysis, or interpretation of the research findings. All data included in the present paper were extracted from peer-reviewed published literature. All analyses performed are transparent and reproducible.

D. D. A. contributed to the writing, analysis, and literature review; L. M. M. contributed to the data extraction and literature review; P. J. M. contributed to the writing, technical and editorial review; C. A. C. contributed to the data extraction, database management, and editorial review.

The authors declare no conflicts of interest.

\section{References}

1. Linos E \& Willett W (2009) Meat, dairy and breast cancer: do we have an answer? Am J Clin Nutr 90, 455-456.

2. Hems G (1970) Epidemiological characteristics of breast cancer in middle and late age. Br J Cancer 24, 226-234.

3. Armstrong B \& Doll R (1975) Environmental factors and cancer incidence and mortality in different countries, with special reference to dietary practices. Int $J$ Cancer 15, 617-631.

4. La Vecchia C \& Pampallona S (1986) Age at first birth, dietary practices and breast cancer mortality in various Italian regions. Oncology 43, 1-6.

5. Serra-Majem L, La Vecchia C, Ribas-Barba L, et al. (1993) Changes in diet and mortality from selected cancers in southern Mediterranean countries, 1960-1989. Eur J Clin Nutr 47, Suppl. 1, S25-S34.

6. Gray GE, Pike MC \& Henderson BE (1979) Breast-cancer incidence and mortality rates in different countries in relation to known risk factors and dietary practices. Br J Cancer 39, $1-7$.

7. Boyd NF, Martin LJ, Noffel M, et al. (1993) A meta-analysis of studies of dietary fat and breast cancer risk. $\mathrm{Br} J$ Cancer 68, 627-636.

8. Missmer SA, Smith-Warner SA, Spiegelman D, et al. (2002) Meat and dairy food consumption and breast cancer: a pooled analysis of cohort studies. Int J Epidemiol 31, 78-85.

9. Taylor VH, Misra M \& Mukherjee SD (2009) Is red meat intake a risk factor for breast cancer among premenopausal women? Breast Cancer Res Treat 117, 1-8.

10. Kabat GC, Cross AJ, Park Y, et al. (2009) Meat intake and meat preparation in relation to risk of postmenopausal breast cancer in the NIH-AARP Diet and Health Study. Int J Cancer 124, 2430-2435.

11. Cross AJ, Leitzmann MF, Gail MH, et al. (2007) Prospective study of red and processed meat intake in relation to cancer risk. PLoS Med 4, e325. 
12. Larsson SC, Bergkvist L \& Wolk A (2009) Long-term meat intake and risk of breast cancer by oestrogen and progesterone receptor status in a cohort of Swedish women. Eur J Cancer 45, 3042-3046.

13. Pala V, Krogh V, Berrino F, et al. (2009) Meat, eggs, dairy products, and risk of breast cancer in the European Prospective Investigation into Cancer and Nutrition (EPIC) cohort. Am J Clin Nutr 90, 602-612.

14. Ferrucci LM, Cross AJ, Graubard BI, et al. (2009) Intake of meat, meat mutagens, and iron and the risk of breast cancer in the Prostate, Lung, Colorectal, and Ovarian Cancer Screening Trial. Br J Cancer 101, 178-184.

15. Egeberg R, Olsen A, Autrup H, et al. (2008) Meat consumption, $\mathrm{N}$-acetyl transferase 1 and 2 polymorphism and risk of breast cancer in Danish postmenopausal women. Eur J Cancer Prev 17, 39-47.

16. Shannon J, Ray R, Wu C, et al. (2005) Food and botanical groupings and risk of breast cancer: a case-control study in Shanghai, China. Cancer Epidemiol Biomarkers Prev 14, 81-90.

17. Taylor EF, Burley VJ, Greenwood DC, et al. (2007) Meat consumption and risk of breast cancer in the UK Women's Cohort Study. Br J Cancer 96, 1139-1146.

18. van der Hel OL, Peeters PH, Hein DW, et al. (2004) GSTM1 null genotype, red meat consumption and breast cancer risk (The Netherlands). Cancer Causes Control 15, 295-303.

19. Cho E, Chen WY, Hunter DJ, et al. (2006) Red meat intake and risk of breast cancer among premenopausal women. Arch Intern Med 166, 2253-2259.

20. Frazier AL, Li L, Cho E, et al. (2004) Adolescent diet and risk of breast cancer. Cancer Causes Control 15, 73-82.

21. Michels KB, Rosner BA, Chumlea WC, et al. (2006) Preschool diet and adult risk of breast cancer. Int J Cancer 118, 749-754.

22. Holmes MD, Colditz GA, Hunter DJ, et al. (2003) Meat, fish and egg intake and risk of breast cancer. Int $J$ Cancer 104, $221-227$.

23. Warriss PD (2000) Meat Science: An Introductory Text. Wallingford, UK: CABI Publishing.

24. Santarelli RL, Pierre F \& Corpet DE (2008) Processed meat and colorectal cancer: a review of epidemiologic and experimental evidence. Nutr Cancer 60, 131-144.

25. Pooling Project of Prospective Studies of Diet and Cancer (2003) Brief description of the Pooling Project and component studies. http://www.hsph.harvard.edu/poolingproject/ about.html

26. Gertig DM, Hankinson SE, Hough H, et al. (1999) $N$-acetyl transferase 2 genotypes, meat intake and breast cancer risk. Int $J$ Cancer 80, 13-17.
27. Mills PK, Beeson WL, Phillips RL, et al. (1989) Dietary habits and breast cancer incidence among Seventh-Day Adventists. Cancer 64, 582-590.

28. Voorrips LE, Brants HA, Kardinaal AF, et al. (2002) Intake of conjugated linoleic acid, fat, and other fatty acids in relation to postmenopausal breast cancer: the Netherlands Cohort Study on Diet and Cancer. Am J Clin Nutr 76, 873-882.

29. Greenland S \& Longnecker MP (1992) Methods for trend estimation from summarized dose-response data, with applications to meta-analysis. Am J Epidemiol 135, 1301-1309.

30. Berlin JA, Longnecker MP \& Greenland S (1993) Metaanalysis of epidemiologic dose-response data. Epidemiology 4, 218-228.

31. Rothstein HR, Sutton AJ \& Borenstein M (2005) Publication Bias in Meta-Analysis: Prevention, Assessments, and Adjustments. Chichester, UK: John Wiley and Sons, Ltd.

32. Rothman K (2004) Episheet software: spreadsheets for the analysis of epidemiologic data. http://members.aol.com/ krothman/episheet.xls

33. Byrne C, Ursin G \& Ziegler RG (1996) A comparison of food habit and food frequency data as predictors of breast cancer in the NHANES I/NHEFS cohort. J Nutr 126, 2757-2764.

34. Linos E \& Willett WC (2007) Diet and breast cancer risk reduction. J Natl Compr Canc Netw 5, 711-718.

35. De Stefani E, Ronco A, Mendilaharsu M, et al. (1997) Meat intake, heterocyclic amines, and risk of breast cancer: a case-control study in Uruguay. Cancer Epidemiol Biomarkers Prev 6, 573-581.

36. Steck SE, Gaudet MM, Eng SM, et al. (2007) Cooked meat and risk of breast cancer - lifetime versus recent dietary intake. Epidemiology 18, 373-382.

37. Sinha R, Gustafson DR, Kulldorff M, et al. (2000) 2-Amino1-methyl-6-phenylimidazo[4,5-b]pyridine, a carcinogen in high-temperature-cooked meat, and breast cancer risk. J Natl Cancer Inst 92, 1352-1354.

38. Delfino RJ, Sinha R, Smith C, et al. (2000) Breast cancer, heterocyclic aromatic amines from meat and $\mathrm{N}$-acetyltransferase 2 genotype. Carcinogenesis 21, 607-615.

39. Deitz AC, Zheng W, Leff MA, et al. (2000) $N$-acetyltransferase-2 genetic polymorphism, well-done meat intake, and breast cancer risk among postmenopausal women. Cancer Epidemiol Biomarkers Prev 9, 905-910.

40. Han DF, Ma J, Zhou X, et al. (2004) A case-control study on the risk of female breast cancer in Wuhan area (article in Chinese). Zhonghua Liu Xing Bing Xue Za Zhi 25, 256-260.

41. Zheng W, Gustafson DR, Sinha R, et al. (1998) Well-done meat intake and the risk of breast cancer. J Natl Cancer Inst 90, 1724-1729. 